\title{
Study of Risk Factors and Management of Abdominal Wound Dehiscence
}

\author{
Vinay Sagar Cheeti $^{1}$, D Asha ${ }^{2}$, B Raju ${ }^{3}$ \\ ${ }^{1}$ Associate Professor, Department of General surgery, Government Medical College, Siddipet, ${ }^{2}$ Post Graduate, Department \\ of General Surgery, Osmania Medical College/Hospital, Hyderabad, ${ }^{3}$ Professor, Department of General Surgery, Osmania \\ Medical College/hospital, Hyderabad, India
}

Corresponding author: Dr D Asha, Post Graduate, Department of General Surgery, Osmania Medical College/Hospital, Hyderabad, India

DOI: http://dx.doi.org/10.21276/ijcmsr.2018.3.4.3

How to cite this article: Vinay Sagar Cheeti, D Asha, B Raju. Study of risk factors and management of abdominal wound dehiscence. International Journal of Contemporary Medicine Surgery and Radiology. 2018;3(4):D10-D13.

\section{A B S T R A C T}

Introduction: Dehiscence of abdominal wound is easily the most notorious complication observed in abdominal surgery. It is disturbing for both to the patient and the treating surgeon. Abdominal wound dehiscence has significant impact on health care cost, both for patients and hospitals. This study was aimed to elucidate factors contributing to abdominal wound dehiscence.

Material and methods: This was a longitudinal study in 31 patients who developed burst abdomen following various types of laparotomies from July 2016 to November 2017, participated in this study.

Results: Burst abdomen common during $3^{\text {rd }}, 4^{\text {th }}, 5^{\text {th }}$ and $6^{\text {th }}$ decades. In study $71 \%$ Male and $29 \%$ Female and Female to Male ratio being 7:3 showing a clear predilection towards male sex. $94 \%$ of cases of burst abdomen followed midline incision. $86.5 \%$ cases of burst abdomen followed emergency operations in which $73 \%$ cases operated for peritonitis. $48.4 \%$ of cases developed wound infection post operatively. $28.8 \%$ of cases had respiratory tract infection. $64.5 \%$ cases of burst abdomen followed in patients with Anaemia. When HB less than 11 gm\% taken a criteria. Out of 31 cases is only 20 cases serum protein measured in which $65 \%$ of Cases of 13 cases having Hypoproteinaemia. Majority of patients $54 \%(17)$ had wound disruption occurring between the sixth to tenth post operative day.

Conclusion: In majority of patient of post op abdominal wound dehiscence there is associated hypoproteinaemia. Finally it appears that post operative wound disruptions are usually local manifestation of a generalized failure of the healing process.

Key Words: Risk Factors, Abdominal Wound Dehiscence

\section{INTRODUCTION}

Dehiscence of abdominal wound mortality rates reported as high as $15 \%-45 \% .^{2}$ The incidence is ranged from $0.4 \%$ to $3.5 \%$ in all laparotomies. ${ }^{3}$ Whereas our country data stated still higher frequency of burst abdomen with overall rate of $4.8 \%$ and $6.6 \%$. Abdominal wound dehiscence is the disruption of laparotomy wound occurring usually between 5th to 8 th post-operative days. ${ }^{1}$ Wound dehiscence is described as partial or complete disruption of an abdominal wound closure with or without protrusion of abdominal contents. Partial wound dehiscence is defined by separation of facial edges without evisceration and occasionally, fibrin covered intestinal loops. Complete wound dehiscence is defined as full separation of fascia and skin with evisceration of intestinal loops.

Post operation wound disruption or evisceration is inescapable responsibility of the surgeon who made the wound. Usually such a complication implies inadequate, preoperative treatment, improper postoperative management and rarely in good hands, poor surgical technique. Frequently a wound disrupts because of the disease, urgent need for operative intervention may preclude satisfactory preoperative preparation of the patient or drainage of abscess or perforation of a viscus may result in continuous and unavoidable contamination of the wound. Wound disruption is defined as a separation of all layers of the incision. It may be partial or complete. Partial when one or more layers have separated but either the skin or the peritoneum remains intact. Complete when all the layers of the abdominal wall have burst apart and this may or may not be associated with protrusion of a viscus evisceration. This study was aimed to elucidate factors contributing to abdominal wound dehiscence.

\section{MATERIAL AND METHODS}

This was a longitudinal study. Thirty one patients who developed burst abdomen following various types of laparotomies in Osmania General Hospital from July 2016 to November 2017, participated in this study.

Patients were selected randomly. Detailed history with specific reference to previous surgery, pre-op medical condition, Post-op period was verified with available records. Inclusion Criteria 
All patients with burst abdomen during the study period have been included.

\section{Exclusion Criteria}

1. Patients lost the follow up.

2. Died during treatment.

The following etological factors are studied.

- Sex

- Age

- Indication for surgery

- Incisions - mid line, cheron (Roof top),

- Anemia - Hb $11 \mathrm{G} \%$ or less is taken as anaemia for this study. $\mathrm{Hb}$ is estimated by Sahli's method.

- Hypo proteinemia-total proteins $6 \mathrm{G} \%$ Or less is considered as hypoproteinaemia for this study. Sr. Proteins are estimated by Biuret Method.

- Post op wound infection. Culture and sensitivity are studied by

- Post op respiratory tract infection is suspected by clinical exam c/o dyspnea and cough on Lung Auscultation: diffuse bilateral crepts.

- Chest $\mathrm{x}$ ray: Pnemonitis and pleural effusions.

\section{RESULTS}

A total of 31 cases were included in the study which were fully managed in osmania general hospital, during the study period and also included the cases that were referred from gynaecological ward.

In this series burst abdomen was common during $3^{\text {rd }}, 4^{\text {th }}, 5^{\text {th }}$ and $6^{\text {th }}$ decades. In this series burst abdomen is seen in $71 \%$ Male and 29\% Female and Female to Male ratio being 7:3 showing a clear predilection towards male sex. In this series $94 \%$ of cases of burst abdomen followed midline incision (table-1).

The presenting complaints were abdominal pain (54\%), fever (19\%), vomiting (19\%), weight loss (6\%), and cough(19\%) (figure-1). None of these complaints occurred in isolation. Each patient had a t least two of the above complaints, Clinical evaluation revealed fever was the most frequent finding (12 patients). Mothers undergoing caesarean section had physiological abdominal distension which was not considered as a clinical sign (figure-2). Dehydration and tachycardia were the other common physical findings while

\begin{tabular}{|l|c|c|}
\hline Age group year & Total No.of cases & Percentage \\
\hline $0-10$ & Nil & $0 \%$ \\
\hline $10-20$ & Nil & $0 \%$ \\
\hline $20-30$ & 4 & $12.9 \%$ \\
\hline $30-40$ & 10 & $32.6 \%$ \\
\hline $40-50$ & 7 & $26.6 \%$ \\
\hline $50-60$ & 5 & $16.1 \%$ \\
\hline$>60$ & 5 & $16.1 \%$ \\
\hline Sex & 22 & $71 \%$ \\
\hline M & 9 & $29 \%$ \\
\hline F & 29 & $93.5 \%$ \\
\hline Type of Incision & 2 & $6.5 \%$ \\
\hline Midline & & \\
\hline Chevron & \multicolumn{2}{|c|}{} \\
\hline \multicolumn{2}{|c|}{ Table-1: Demographic distribution in study } \\
\hline
\end{tabular}

\begin{tabular}{|l|c|c|}
\hline Wound infection & No. of Cases & Percentage \\
\hline Present & 15 & $48.4 \%$ \\
\hline Absent & 16 & $51.6 \%$ \\
\hline Respiratory Infection & & \\
\hline Present & 8 & $25.8 \%$ \\
\hline Absent & 23 & $74.2 \%$ \\
\hline Anaemia & & \\
\hline Present & 20 & $64.5 \%$ \\
\hline Absent & 11 & $35.5 \%$ \\
\hline Hypoproteinaemia & & \\
\hline Present & 13 & $65 \%$ \\
\hline Absent & 7 & $35 \%$ \\
\hline \multicolumn{2}{|l}{} \\
\hline
\end{tabular}

\begin{tabular}{|l|c|c|}
\hline Age & Mendoza et al $^{\mathbf{5}}$ & Present series $^{-1}$ \\
\hline $0-10$ & - & $0 \%$ \\
\hline $10-20$ & - & $0 \%$ \\
\hline $20-30$ & - & $12.9 \%$ \\
\hline $30-40$ & $7.1 \%$ & $12.6 \%$ \\
\hline $40-50$ & $20.1 \%$ & $26.6 \%$ \\
\hline $50-60$ & $20.1 \%$ & $16.1 \%$ \\
\hline$>60$ & $48 \%$ & $16.1 \%$ \\
\hline \multicolumn{2}{|c|}{ Table-3: Age Distribution in our study in comparison with } \\
others \\
\hline
\end{tabular}

\begin{tabular}{|l|c|c|c|}
\hline Type of surgery & $\begin{array}{c}\text { Mendoza } \\
\text { et al }^{\mathbf{5}}\end{array}$ & $\begin{array}{c}\text { Lehman } \\
\text { et a }^{\mathbf{6}}\end{array}$ & $\begin{array}{c}\text { Present } \\
\text { series }\end{array}$ \\
\hline Emergency & $60 \%$ & - & $77.4 \%$ \\
\hline Elective & $40 \%$ & - & $22.6 \%$ \\
\hline Peritonitis & $86.8 \%$ & $84 \%$ & $77.4 \%$ \\
\hline Malignancy & - & $16 \%$ & $9.7 \%$ \\
\hline Obstruction & $13.2 \%$ & - & $12.9 \%$ \\
\hline Type of Incision & & & \\
\hline Midline & - & $87 \%$ & $93.5 \%$ \\
\hline Chevron & - & - & $6.5 \%$ \\
\hline \multicolumn{4}{|r|}{ Table-4: Indication and type of surgery } \\
\hline
\end{tabular}

\begin{tabular}{|l|c|c|}
\hline Wound infection & Alexander et al $^{\mathbf{8}}$ & Present series \\
\hline Present & $14 \%$ & $48.4 \%$ \\
\hline Absent & $86 \%$ & $51.6 \%$ \\
\hline Resp. Infection & $24 \%$ & $25.8 \%$ \\
\hline Present & $76 \%$ & $74.2 \%$ \\
\hline Absent & Table-5: Hypoproteinemia and anemia in comparison with \\
other studies \\
\hline
\end{tabular}

wasting, abdominal masses and distension of abdomen occurred in few patients,

In this series $86.5 \%$ cases of burst abdomen followed emergency operations in which $73 \%$ cases operated for peritonitis (figure-3).

In this series $48.4 \%$ of cases developed wound infection post operatively. $28.8 \%$ of cases had respiratory tract infection. 64.5\% cases of burst abdomen followed in patients with Anaemia. When HB less than $11 \mathrm{gm} \%$ taken a criteria. out of 31 cases is only 20 cases serum protein measured in which $65 \%$ of Cases of 13 cases having Hypoproteinaemia (table-2). 


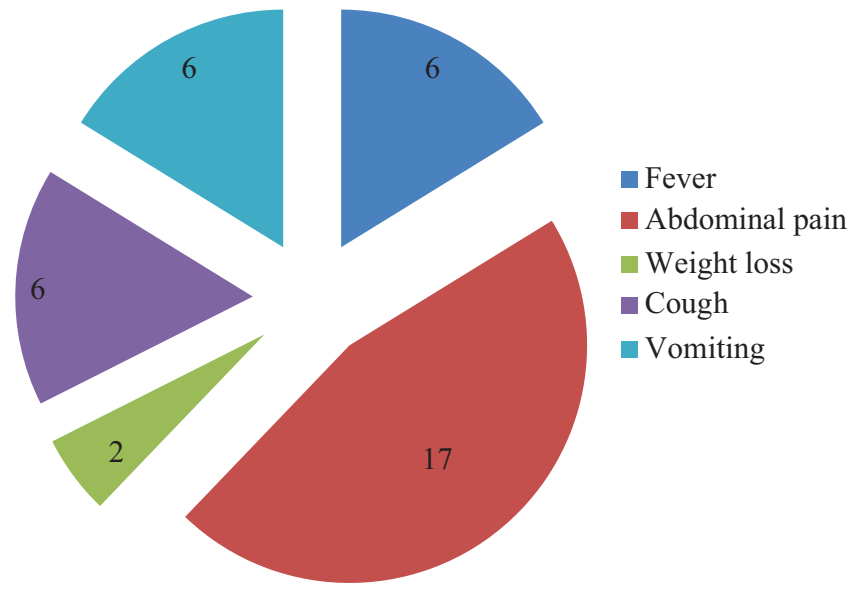

Figure-1: Initial complaints

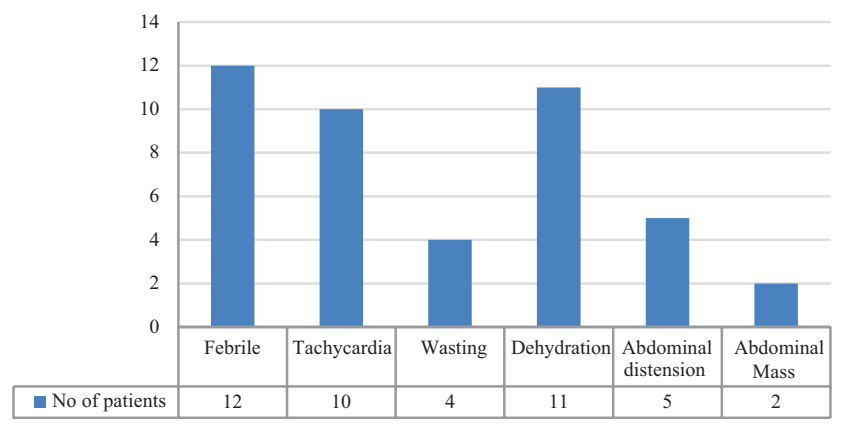

Figure-2: Physical findings

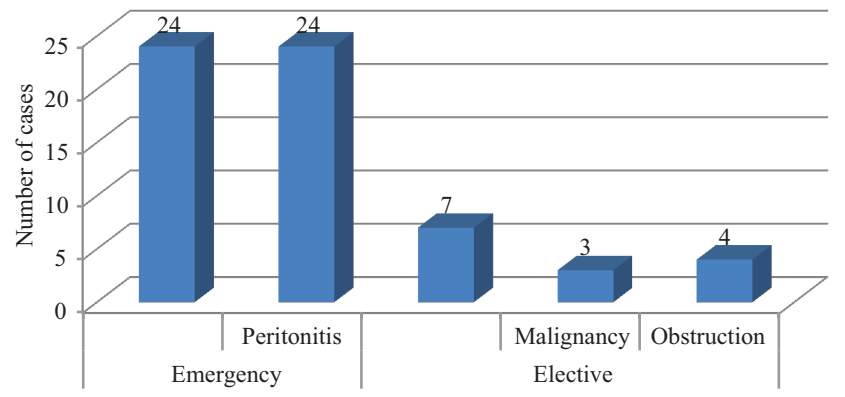

Figure-3: Indication for surgery in study

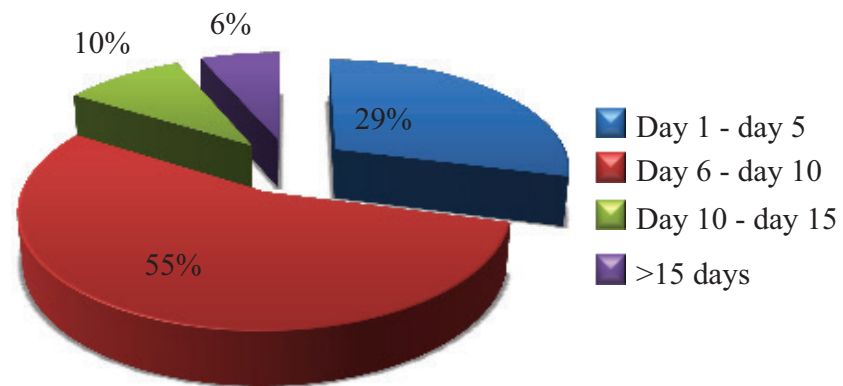

Figure-4: Post operative day when dehiscence occured
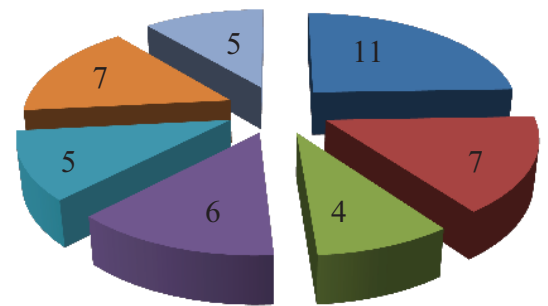

Infection /peritonitis

- Loose sutures /knots Damaged suture

- Cut fascia margins

Early suture removal

Haematoma

Figure-5: Relaparotomy findings
Majority of patients 54\%(17) had wound disruption occurring between the sixth to tenth post operative day. There were 9 patients (29\%) who developed wound dehiscence between one o five days. There were only two patients who developed disruption after day fifteen (figure-4).

As demonstrated in figure 5 the relaparotomy findings varied. In the descending order were peritonitis, haematoma, loose sutures / knots cut fascia margins, early removal of sutures, and poor wound closure techniques.

\section{DISCUSSION}

Thirty one patients participated in this study during July 2016 to November 2017.

In this series burst abdomen wasfound commonly in Beyond 30years Peak incidence in 30-40 years age group (table-3). Mendoza et $\mathrm{al}^{5}$ also found more incidence in IV, $\mathrm{V}$ and above $\mathrm{V}$ decade.

In this series $71 \%$ were males. Male to female ratio was 7:3. Lehman et al ${ }^{6}$ and Rodríguez-Hermosa $\mathrm{JI}^{7}$ et al also found more incidence among males. Preponderance of burst of the abdomen in males is thought to be due to the greater ability of the Male to raise his intra abdominal pressure. Abdominal breathing, greater physical activity, less Elasticity of abdominal wall, increase the incidence of burst abdomen in males. Increased incidence in older age explained by associated nutritional disorders, pulmonary complications cancer and other afflications of the aged.

In this series $77.4 \%$ of cases of burst abdomen followed emergency surgery. Mendoza et $\mathrm{al}^{5}$ found $60 \%$ of burst abdomen cases followed emergency surgery which is nearer to present series. In our study $9.7 \%$ of cases of burst abdomen developed in patients underwent surgery for malignancy It was $16 \%$ Lehman et al series. Increased incidence of burst abdomen in emergency situation may be due to urgent need for Operative intervention may preclude satisfactory preoperative preparation of patients. Perforation of a viscus or drainage of abscess may result in continuous and unavoidable contamination of wound.

In this series $93.5 \%$ of cases of burst abdomen occurred in midline incision. In Lehman series Burst abdomen followed in $87 \%$ of cases. Anatomic incision should have preference over the non anatomical incisions or vertical incisions.

High incidence of disruptions in wounds of upper abdomen believed that relative tenseness of the muscles and fascia in this area due to attachment to the thoracis cage. Sloan demonstrated that the strain upon a vertical incision produced by lateral abdominal muscles is 30 times that of transverse incision.

In this series $64.5 \%$ of case having anaemia. It indicates that anaemia having a major role in producing burst abdomen in our series. Where as Lehman and Alexander series it is seen $11 \%$ and $3 \%$ respectively.

When serum proteins Lower limit taken as $6 \mathrm{gm} \%, 65 \%$ of our series shown hypoproteinaemia. Which is almost equal to Shetty ARS et $\mathrm{al}^{9}$ series findings. Wound infection present in $48.4 \%$ cases of burst abdomen in our series. In comparison in White and Alexander series ${ }^{8}$ the role of wound infection in burst abdomen appeared less. Respiratory infection was present in $25.8 \%$ of cases of burst abdomen in our series, 
which is similar to Alexander series ${ }^{8}$ in which $26 \%$ cases had respiratory infection. Mahey $\mathrm{R}$ et $\mathrm{al}^{10}$ concluded that factors like anaemia, malnutrition, obesity, diabetes mellitus and cough and surgery factors like type of surgery (elective/ emergency), underlying disease and type of incision, type of closure, suturing material and suturing method play important role in development of wound infection and subsequently development of wound dehiscence which correlates well with our study.

\section{CONCLUSION}

Highest incidence of burst abdomen in the present series was in patients above 50 years. Twenty two patients were males. Etiology is multifactorial. Operations for peritonitis were the most common among all operation for the development of burst abdomen. Midline incision is more prone for development of burst abdomen. Post operative wound infection is also a common predisposing factor. Post operative respiratory infection having cough has a major role in occurrence of burst abdomen. Anaemia appears to be one of the important contributing factor for the development post operative abdominal wound disruption. In majority of patient of post op abdominal wound dehiscence there is associated hypoproteinaemia. Finally it appears that post operative wound disruptions are usually local manifestation of a generalized failure of the healing process.

\section{REFERENCES}

1. Irvin TT, Stoddard CJ. Abdominal wound healing: a prospective clinical study. British Med J. 1977;2(6083):351-2.

2. Madsen G, Fisher L, Wara P. Burst abdomen clini- cal features and factors influencing mortality. Danish Med Bulletin. 1992;39(2):183-5.

3. Smith JAR. Clinical Surgery in General. 3 edition. Elsevier. New York. 1999:350.

4. Muneiah NS, Kumar NM, Sabitha P, Prakash DGV. Abdominal wound dehiscence-A look into the risk factors. IOSR Journal of Dental and Medical Sciences. 2015;14(10):47-54.

5. Mendoza C B, Watne A L, Grace JE and Moore G E. American Journal of Surgery 1966;112(1):839-845.

6. Lehman JA, Cross F S and Partington P F. Surgery, G T S and Partington P F. Surgery, Gynecology and Obstetrics 1968;126(3):1235-1241.

7. Rodríguez-Hermosa JI, Codina-Cazador A, Ruiz B, Roig J, Gironés J, Pujadas M, Pont J, Aldeguer X, Aceroc D. Risk factors for acute dehiscence of the abdominal wall after laparotomy in adults. Spanish Surg. 2005;77(5):280-6.

8. Alexander JW, Rahn R et al. Prevention of surgical site infections by an infusion of topical antibiotics in morbidly obese patients. Surg Infect 2009;(6): 53-7.

9. Shetty ARS, Rai S, Bhat R, Rao S, Thejeswi P. Comparison of early postoperative complications of laparotomies in diabetics and non-diabetics - a study on south indian population. Internet J Surg. 2013;30(4).

10. Mahey R, Ghetla S, Rajpurohit J, Desai D, Suryawanshi S. A prospective study of risk factors for abdominal wound dehiscence. Int Surg J 2017;4(2):24-8.
Source of Support: Nil; Conflict of Interest: None

Submitted: 02-09-2018; Accepted: 25-09-2018; Published online: 15-10-2018 